\title{
Pengaruh Citra Merek terhadap Niat Beli Konsumen (Studi pada Toyota
} Agya)

\author{
Jeremi Francis Setiadi dan Tommy Setiawan Ruslim \\ Program Studi Manajemen Fakultas Ekonomi \& Bisnis \\ Universitas Tarumanagara \\ Email: Jeremi.115160264@stu.untar.ac.id
}

\begin{abstract}
The purpose of this study is to determine whether 1) brand image significantly influences the consumer price of Toyota Agya cars. 2) brand image significantly influences the perceived quality of consumers of Toyota Agya cars. 3) perceived price significantly influences the purchase intention of Toyota Agya car consumers. 4) perceived quality significantly influences the purchase intention of Toyota Agya car consumers. 5) brand image significantly influences the purchase intention of Toyota Agya car consumers mediated by perceived price. 6) brand image significantly influences the purchase intention of Toyota Agya car consumers mediated by perceived quality. Sample was selected by convenience sampling method with a total of 100 samples. And the results of this study indicate that the brand image has a positive and significant effect on the perceived price and perceived quality of Toyota Agya car consumers, the perceived price has a positive but not significant effect on the purchase intention of Toyota Agya car consumers, perceived quality has a positive and significant effect on the purchase intention of Toyota car consumers Agya, brand image has a positive but not significant effect on consumer purchase intentions mediated by perceived prices, and brand image has a positive and significant effect on consumer purchase intentions mediated by perceived quality
\end{abstract}

Keywords: Image, Price, Quality,Intention, Toyota

Abstrak: Tujuan dari penelitian ini adalah untuk mengetahui apakah 1) Brand image berpengaruh secara signifikan terhadap perceived price konsumen mobil Toyota Agya. 2) Brand image berpengaruh secara signifikan terhadap perceived quality konsumen mobil Toyota Agya. 3) Perceived price berpengaruh secara signifikan terhadap purchase intention konsumen mobil Toyota Agya. 4) Perceived quality berpengaruh secara signifikan terhadap purchase intention konsumen mobil Toyota Agya. 5) Brand image berpengaruh secara signifikan terhadap purchase intention konsumen mobil Toyota Agya yang dimediasi oleh perceived price. 6) Brand image berpengaruh secara signifikan terhadap purchase intention konsumen mobil Toyota Agya yang dimediasi oleh perceived quality. Sampel dipilih dengan metode convenience sampling dengan jumlah sebanyak 100 sampel. Dan hasil penelitian ini menunjukkan bahwa brand image berpengaruh positif dan signifikan terhadap perceived price dan perceived quality konsumen mobil Toyota Agya, perceived price berpengaruh positif tetapi tidak signifikan terhadap purchase intention konsumen mobil Toyota Agya, perceived quality berpengaruh positif dan signifikan terhadap purchase intention konsumen mobil Toyota Agya, brand image berpengaruh positif tetapi tidak signifikan terhadap purchase intention konsumen yang dimediasi oleh perceived price, dan brand image berpengaruh positif dan signifikan terhadap purchase intention konsumen yang dimediasi oleh perceived quality

Kata kunci: Citra, Harga, Kualitas, Niat, Toyota 


\section{LATAR BELAKANG}

Meningkatnya kendaraan roda empat maupun dua di Jakarta saat ini mengakibatkan kemacetan yang selalu terjadi di DKI Jakarta. Hal ini diakibatkan karena tingginya niat beli masyarakat untuk memiliki kendaraan. Banyak masyarakat Indonesia membeli mobil hanyalah untuk mengikuti lifestyle zaman sekarang, ataupun agar tidak kehujanan / kepanasan karena musim yang ada di Indonesia. Karena hal ini, beberapa produsen mobil di Indonesia mulai memproduksi mobil dengan kategori Low Cost Green Car(LCGC). Tetapi, pada tahun 2019 telah terjadi penurunan niat beli yang cukup signifikan pada Toyota Agya .

Menurut Kinnear \& Taylor (1995), purchase intention merupakan bagian dari komponen perilaku konsumen dalam sikap mengkonsumsi, kecenderungan responden untuk bertindak sebelum keputusan membeli benar-benar dilaksanakan. Berdasarkan penelitian terdahulu, banyak faktor yang mempengaruhi purchase intention. Wang dan Chen (2016) menunjukkan bahwa perceived price memiliki pengaruh positif kepada perceived value, perceiver risk, maupun purchase intention, perceived risk memiliki pengaruh positif kepada purchase intention dan purchase situation memberi pengaruh positif kepada purchase intention. Moslehpour et al., (2015) menjelaskan bahwa product characteristics dan perceived price secara signifikan berpengaruh terhadap purchase intention konsumen. Tansil dan Tielung (2014) menyatakan bahwa perceived price dan perceived quality memiliki efek yang signifikan terhadap purchase intention konsumen. Suhud dan Wilson (2019) juga menunjukkan hasil bahwa brand image mempengaruhi perceived price dan perceived quality yang kemudian mempengaruhi purchase intention.

\section{KAJIAN TEORI}

Teori ini mengacu pada Theory of Planned Behavior(TPB). TPB digunakan untuk menjelaskan niat yang kemudian mempengaruhi perilaku seseorang. Ajzen (2005) mengatakan bahwa niat dibentuk oleh tiga faktor, yaitu sikap, norma subjektif, dan kontrol perilaku. Jadi, dapat diketahui bahwa TPB adalah niat yang timbul dari diri seseorang untuk melakukan sesuatu dan niat tersebut dipengaruhi oleh beberapa faktor.

Brand Image. Setiadi (2003) berkata bahwa brand image adalah "representasi dari keseluruhan persepsi terhadap merek dan dibentuk dari informasi dan pengalaman masa lalu terhadap merek itu".Kotler dan Keller (2009) mengatakan bahwa brand image adalah "nama, istilah, tanda, simbol, atau rancangan, atau kombinasi dari semuanya, yang dimaksudkan untuk mengidentifikasi barang atau jasa atau kelompok penjual dan untuk mendiferensiasikannya (membedakan) dari barang atau jasa pesaing".Menurut Schiffman \& Kanuk (2007) "brand image adalah sekumpulan asosiasi mengenai suatu merek yang tersimpan dalam benak atau ingatan konsumen".

Perceived Price. Menurut Kotler \& Armstrong (2008) perceived price adalah "sejumlah uang yang ditagihkan atas suatu produk dan jasa atau jumlah dari nilai yang ditukarkan para pelanggan untuk memperoleh manfaat dari memiliki atau menggunakan suatu produk atau jasa".Peter \& Olson (2008) mengatakan bahwa perceived price adalah "bagaimana informasi harga dipahami seluruhnya oleh konsumen dan memberikan makna yang dalam bagi mereka".Menurut Schiffman \& Kanuk (2007) perceived price adalah "pandangan atau persepsi mengenai harga bagaimana konsumen memandang harga tertentu (tinggi, rendah, wajar) mempengaruhi pengaruh yang kuat terhadap maksud membeli dan kepuasan membeli”. 
Perceived Quality. Menurut Laksana (2008) perceived quality merupakan "sejumlah keistimewahan produk yang memenuhi keinginan pelanggan dengan demikian memberikan kepuasan atas penggunaan produk".Menurut Durianto (2004) perceived quality merupakan "persepsi pelanggan terhadap keseluruhan kualitas atau keunggulan suatu produk atau jasa layanan yang berkaitan dengan apa yang diharapkan pelanggan".Menurut Keller (2013) perceived quality merupakan "persepsi konsumen tentang suatu merek sebagai refleksi dari asosiasi merek yang ada pada pikiran konsumen".

Purchase Intention. Menurut Kotler (2005)purchase intention merupakan "sesuatu yang timbul setelah menerima rangsangan dari produk yang dilihatnya, dari sana timbul ketertarikan untuk mencoba produk tersebut sampai pada akhirnya timbul keinginan untuk membeli agar dapat memilikinya".Menurut Schiffman \& Kanuk (2007) "purchase intention adalah suatu kekuatan psikologis yang di dalam individu, yang berdampak pada melakukan sebuah tindakan".Menurut Mowen \& Minor (2007) "purchase intention merupakan penentuan dari pembeli untuk melakukan suatu tindakan seperti membeli suatu produk atau jasa".

Kaitan antara Brand Image dan Perceived Price. Pada penelitian sebelumnya yang dilakukan oleh Lien et al., (2015) terhadap online hotel booking.Dan hasil yang didapatkan bahwa brand image berpengaruh secara signifikan dan positif pada perceived pricepenelitian tersebut. Penelitian yang dilakukan Lee et al., (2017) tentang chinese hotel industry menghasilkan penelitian bahwa brand image berpengaruh signifikan terhadap perceived price. Dan penelitian yang dilakukan Iskandar et al., (2018) terhadap para pengguna smartphone Samsung S8 menghasilkan bahwa brand image memiliki pengaruh yang signifikan terhadap perceived price.

Kaitan antara Brand Image dan Perceived Quality. Penelitian yang dilakukan Deniz et al., (2019) terhadap personal care products diketahui bahwa adanya pengaruh yang signifikan antara brand image terhadap perceived quality. Lalu penelitian yang dilakukan Aberdeen et al., (2016) terhadap carbonated drink di Bogor menghasilkan bahwa brand image pada minuman Big Cola maupun Coca Cola memberikan pengaruh yang signifikan terhadap perceived quality. Dan penelitian yang dilakukan Cakmak (2016) dalam membentukn brand trust menjelaskan bahwa adanya dampak positif yang diberikan antara brand image terhadap perceived quality pada produk teknologi.

Kaitan antara Perceived Price dan Purchase Intention. Penelitian yang dilakukan Leonika (2017) terhadap traditional fabrics menghasilkan bahwa perceived price berpengaruh secara positif terhadap purchase intention. Moslehpour et al., (2015) meneliti tentang produk roti yang menghasilkan bahwa perceived price berpengaruh positif dan signifikan terhadap purchase intention pada produk roti. Wang et al., (2016) meneliti tentang low-cost carriers menghasilkan penelitian bahwa perceived price berpengaruh terhadap purchase intention.

Kaitan antara Perceived Qualitydan Purchase Intention. Tansil et al., (2014) meneliti tentang cupcakes dan pada penelitiannya memberikan hasil bahwa perceived quality terhadap purchase intention diterima. Penelitian yang dilakukan Leonika (2017) terhadap traditional fabrics menghasilkan bahwa perceived quality menjadi salah satu penentu konsumen dalam membeli kain. Saleem et al., (2015) meneliti tentang consumer satisfaction dan didalamnya terdapat 
kaitan antara perceived quality dan purchase intention dan hasilnya menunjukkan bahwa perceived quality memberikan hasil yang signifikan terhadap purchase intention.

Kaitan antara Brand Image dan Purchase Intention yang dimediasi Perceived Price. Lien et al., (2015) meneliti tentang online hotel booking menghasilkan penelitian bahwa adanya pengaruh positif yang terjadi antara brand image terhadap purchase intention yang dimediasi oleh perceived price. Arini et al., (2019) dengan penelitian tentang niat beli konsumen menghasilkan bahwapersepsi harga memediasi pengaruh positif brand image terhadap niat beli konsumen Pie Susu Asli Enaaak di kota Denpasar. Dan penelitian yang dilakukan Suarjana et al., (2018) menghasilkan bahwa ada pengaruh yang signifikan terhadap brand image dengan perceived price terhadap purchase intention konsumen Indihome.

Kaitan antara Brand Image dan Purchase Intention yang dimediasi Perceived Quality. Penelitian yang dilakukan Aberdeen et al., (2016) terhadap carbonated drink di Bogor menyatakan bahwa adanya pengaruh yg signifikan dari brand image terhadap purchase intention yang dimediasi oleh perceived quality pada minuman Coca Cola maupun Big Cola. Wang et al., (2014) meneliti tentang evidence from award winning mutual fundsmenunjukkan adanya efek positif dan pengaruh langsung terhadap brand image, perceived quality, dan purchase intention. Dan penelitian yang dilakukan Tee et al., (2015) meneliti tentang branded clothes di Jakarta menghasilkan bahwa brand image dan perceived quality memiliki hubungan yang kuat dan saling berhubugan dengan purchase intention.

Berdasarkan penjelasan di atas, maka model dan hipotesis penelitian dalam penelitian ini adalah sebagai berikut.

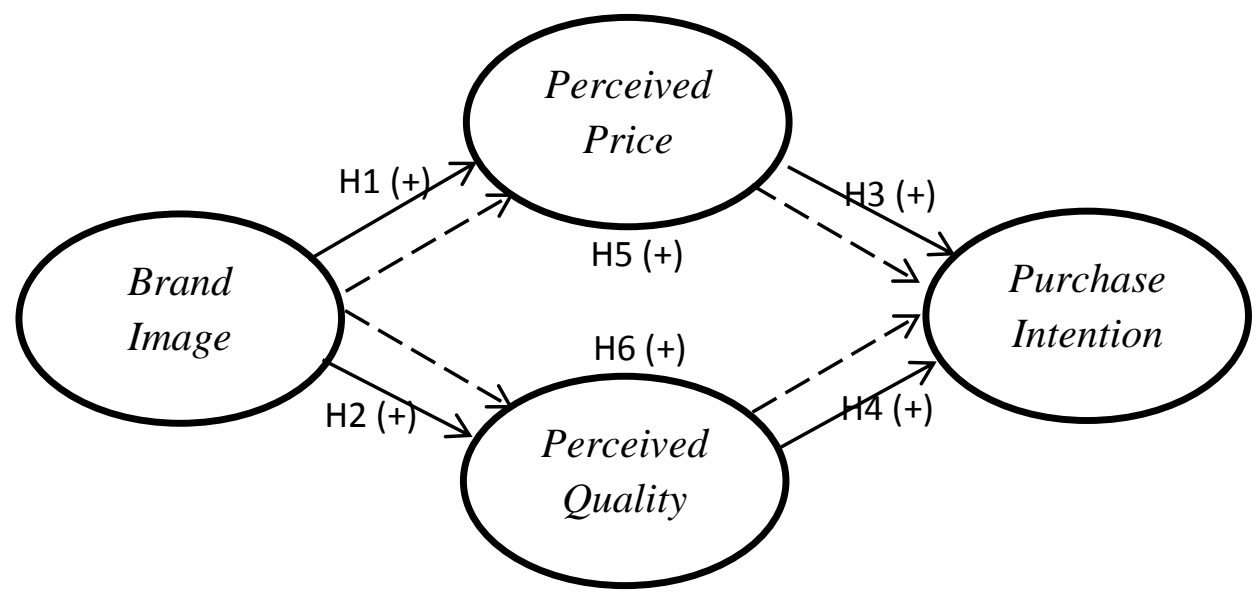

Gambar 1. Model Penelitian

H1: Brand image berpengaruh positif dan signifikan terhadap perceived price konsumen.

H2: Brand image berpengaruh positif dan signifikan terhadap perceived quality konsumen.

H3: Perceived price berpengaruh positif dan signifikan terhadap purchase intention konsumen.

H4: Perceived quality berpengaruh positif dan signifikan terhadap purchase intention konsumen.

H5: Brand image berpengaruh positif dan signifikan terhadap purchase intention konsumen yang dimediasi oleh perceived price.

H6: Brand image berpengaruh positif dan signifikan terhadap purchase intention konsumen yang 
dimediasi oleh perceived quality.

\section{METODOLOGI}

Penelitian ini merupakan penelitian deskriptif menggunakan cross sectional research. Sampel diambil menggunakan non-probability sampling dengan metode convenience sampling. Dan pada penelitian ini mengambil 100 responden pengguna mobil Toyota Agya di wilayah DKI Jakarta.Subyek penelitian ini berdasarkan jenis kelamin, umur, pekerjaan, status, pendidikan terakhir, dan pendapatan perbulan. Analisis data diukur dengan menggunakan software SmartPLS. Dan pengujian hipotesis menggunakan uji path coefficient, $\mathrm{f}^{2}, T$-Statistics, dan $P$ Value.

Operasionalisasi variabel pada penelitian ini menggunakan operasionalisasi variabel penelitian sebelumnya dengan sedikit modifikasi yaitu:

Tabel 1. Variabel Penelitian

\begin{tabular}{|c|c|c|}
\hline Variabel & Indikator & Acuan \\
\hline Brand Image & 16 item & \multirow{2}{*}{ Suhud, U., \& Willson, G. } \\
\cline { 1 - 2 } Perceived Price & 8 item & (2019) \\
\hline Perceived Quality & 12 item & \\
\hline Purchase Intention & 6 item & \\
\hline
\end{tabular}

\section{HASIL UJI STATISTIK}

Hasil uji validitas diperlukan sedikit modifikasi sehingga menghasilkan nilai AVE yang valid dengan nilai > 0,5 dan nilai loading factor setiap indikator terdapat nilai yang < 0,7 tetapi masih berada di atas 0,5 sehingga masih dianggap reliabel. Hasil dari cross loading terdapat 2 indikator yang memilik nilai lebih besar daripada nilai cross loadingnya, sehingga dilakukan penghapusan terhadap 2 indikator tersebut sehingga memiliki nilai discriminant validity yang baik. Pada uji reliabilitas, nilai cronbach's alpha $>0,6$,maka instrumen penelitian ini reliabel.

Pada nilai $R$ square perceived price, didapatkan nilai sebesar 51,9\% yang artinyavariabel perceived price dapat dijelaskan oleh variabel brand image, dan sisanya sebesar $48,1 \%$ dijelaskan oleh variabel di luar model penelitian ini.Nilai $\mathrm{R}$ squareperceived quality sebesar $53,1 \%$ yang berarti variabel perceived quality dapat dijelaskan oleh variabel brand image, dan sisanya sebesar $46,9 \%$ dijelaskan oleh variabel di luar model penelitian ini. Dan nilai $\mathrm{R}$ squarepurchase intention sebesar 59,7\% yang berarti variabel purchase intentionmampu dijelaskan oleh variabel perceived price dan perceived quality, dan sisanya sebesar 40,3\% dijelaskan oleh variabel di luar model penelitian ini. Dan pada nilai $\mathrm{Q}^{2}$, variabel purchase intention memiliki nilai sebesar 0,419, variabel perceived price memiliki nilai sebesar 0,307 , dan variabel perceived quality memiliki nilai sebesar 0,328 yang berarti ketiga variabel memiliki nilai predictive relevancekarena $>0$.

Dibawah ini merupakan hasil dari pengujian hipotesis: 
Tabel 2. Hasil Pengujian Hipotesis

\begin{tabular}{|c|c|c|c|c|}
\hline Variabel & $\begin{array}{c}\text { Path } \\
\text { Coefficient }\end{array}$ & $\begin{array}{c}\boldsymbol{T} \text { - } \\
\text { Statistic }\end{array}$ & P-Value & $\mathbf{f}^{\mathbf{2}}$ \\
\hline Brand Image $\rightarrow$ Perceived Price & 0,728 & 16,502 & 0,000 & 1,130 \\
\hline Brand Image $\rightarrow$ Perceived Quality & 0,773 & 17,237 & 0,000 & 1,483 \\
\hline Perceived Price $\rightarrow$ Purchase Intention & 0,101 & 0,970 & 0,333 & 0,010 \\
\hline Perceived Quality $\rightarrow$ Purchase Intention & 0,645 & 7,124 & 0,000 & 0,417 \\
\hline $\begin{array}{c}\text { Brand Image } \rightarrow \text { Perceived Price } \rightarrow \\
\text { Purchase Intention }\end{array}$ & 0,073 & 0,949 & 0,343 & \\
\hline $\begin{array}{c}\text { Brand Image } \rightarrow \text { Perceived Quality } \rightarrow \\
\text { Purchase Intention }\end{array}$ & 0,498 & 5,479 & 0,000 & \\
\hline
\end{tabular}

\section{DISKUSI}

Berdasarkan pada hasil pengujian hipotesis 1 (H1) menunjukkan bahwa brand image berpengaruh positif dan signifikan terhadap perceived price konsumen. Hal ini sesuai dengan hasil dari penelitian online hotel bookingyang dilakukan oleh Lien et al., (2015). Pada penelitian tersebut dikatakan bahwa brand image memiliki dampak yang signifikan dan positif terhadap perceived price karena pada industri hotel maupun industri kendaraan memberikan dampak yang sama ketika kedua industri tersebut memiliki citra yang baik maupun buruk terhadap harga.

Lalu pada hasil pengujian hipotesis $2(\mathrm{H} 2)$ menunjukkan bahwa brand image berpengaruh positif dan signifikan terhadap perceived quality konsumen. Hal ini sesuai dengan hasil dari penelitian Cakmak (2016) yang meneliti tentang kesadaran merek pada citra merek, persepsi kualitas, dan efek pada resiko dalam menciptakan kepercayaan merek. Pada penelitian tersebut menunjukkan bahwa pengaruh citra merek selain kesadaran merek. Dijelaskan bahwa sementara citra merek yang merupakan salah satu faktor pengetahuan merek mengurangi resiko dalam persepsi konsumen, hal tersebut juga meningkatkan persepsi kualitas.

Kemudian pada hasil pengujian hipotesis 3 (H3) menunjukkan bahwaperceived price berpengaruh positif dan tidak signifikan terhadap purchase intention konsumen. Hasil ini tidak sesuai dengan penelitian yang dilakukan Moslehpouret al., (2015). Ketidaksesuaian ini diakibatkan karena perbedaan dari objek yang dibahas. Pada objek roti oleh peneliti sebelumnya memang dikatakan mempengaruhi, karena roti hanya dikonsumsi untuk sekali makan saja, sehingga konsumen lebih mencari kemudahan untuk dikonsumsi dan harga yang murah. Sedangkan pada objek kendaraan, konsumen lebih mencari kemampuan dan fasilitas yang dapat dirasakan dari kendaraan tersebut. Dan kendaraan yang dibeli akan digunakan untuk jangka panjang. Hasil ini menjelaskan bahwa tidak semua konsumen memperhatikan harga produk mobil untuk mempengaruhi niat beli terhadap Toyota Agya.

Pada hasil pengujian hipotesis $4(\mathrm{H} 4)$ menunjukkan bahwa perceived quality berpengaruh positif dan signifikan terhadap purchase intention konsumen. Hal ini sesuai dengan hasil penelitian yang dilakukan oleh Saleem et al., (2015) tentang persepsi kualitas produk dan niat beli terhadap kepuasan pelanggan. Pada penelitian tersebut dikatakan bahwa persepsi kualitas 
berpengaruh terhadap niat beli konsumen pada laptop DELL karena pada industri penelitian sebelumnya maupun industri kendaraan, persepsi kualitas adalah hal yang terpenting dan berpengaruh besar untuk meningkatkan niat beli konsumen.

Hasil pengujian hipotesis 5 (H5) menunjukkan bahwa brand image berpengaruh positif dan tidak signifikan terhadap purchase intentionkonsumenyang dimediasi oleh perceived price. Hal ini tidak sejalan dengan penelitian Lienet al., (2015). Ketidaksesuaian hasil penelitian ini diakibatkan karena objek penelitian yang berbeda. Pada pembahasan penelitian sebelumnya, harga berpengaruh dalam melakukan online booking hotel. Karena apabila ada dua hotel pembanding yang memberikan layanan yang sama dengan citra dari hotel tersebut yang baik tetapi memiliki harga yang berbeda, konsumen pastinya lebih memilih hotel dengan harga yang lebih murah. Karena hal yang dilakukan ketika menginap di suatu hotel hanya untuk jangka pendek, bukan untuk jangka panjang. Sedangkan kendaraan digunakan untuk jangka panjang, orang-orang lebih rela mengeluarkan uang lebih untuk memiliki kendaraan karena citra kendaraan dan kualitas yang dibanding citra yang baik dengan harga yang murah dari suatu kendaraan.

Dan pada pengujian hipotesis 6 (H6) menunjukkan bahwa brand image berpengaruh positif dan signifikan terhadap purchase intentionkonsumenyang dimediasi oleh perceived quality. Hal ini sejalan dengan penelitian yang dilakukan oleh Aberdeen et al., (2016) tentang pengaruh kesadaran merek dan citra terhadap persepsi kualitas konsumen dan niat beli yang dilakukan di kota Bogor. Pada penelitian tersebut dikatakan bahwa adanya pengaruh yang sama pentingnya antara efek langsung dan tidak langsung antara citra merek terhadap niat beli dan citra merek terhadap niat beli melalui persepsi kualitas yang menghasilkan pengaruh yang positif.

\section{KESIMPULAN}

Dari hasil di atas, dapat diketahui bahwa H1, H2, H4, dan $\mathrm{H} 6$ menghasilkan penelitian yang positif dan signifikan, sedangkan pada H3 dan H6 menghasilkan penelitian yang positif tetapi tidak signifikan. Sehingga dari sini dapat dilihat bahwa niat beli konsumen Toyota Agya tidak tumbuh karena persepsi harga konsumen. Disarankan kepada pihak Toyota Agya untuk terus berinovasi terhadap produknya dari sisi interior maupun eksterior sehingga lebih memikat keinginan konsumen untuk membeli. Dan untuk penelitian selanjutnya, disarankan untuk menggunakan variabel lain yang dapat mempengaruhi purchase intention, serta menambah jumlah responden sehingga hasil penelitian dapat lebih kuat untuk direpresentasikan. Disarankan juga untuk menyebar secara langsung agar setiap respon konsumen benar-benar mewakili sampel yang dibutuhkan, dan juga menyederhanakan bahasa pada kuesioner agar responden lebih mudah memahami.

\section{DAFTAR PUSTAKA}

Aberdeen, N. I., Syamsun, M., \& Najib, M. (2016). The Effect of Brand Awareness and Image on Consumer Perceived Quality and Purchase Intension-A Study Case of Carbonated Drink Brand at Bogor City. International Journal of Scientific and Research Publications, 6(8), 441-446.

Ajzen, I. (2005). Attitudes, Personality and Behavior. New York: Open University Press.

Arini, P. E., \& Sudiksa, I. B. (2019).Peran Persepsi Harga Dalam Memediasi Brand Image Terhadap Niat Beli Konsumen. E-Jurnal Manajemen, 8(3), 1665-1695. 
ÇAKIROĞLU, A. D., \& Galaş, C. (2019). KIŞṠISEL BAKIM ÜRÜNLERİNDE MARKA SADAKATININ BELIRLEYİILERİ: GİRESUN İLINDE BİR UYGULAMA. Kafkas Üniversitesi İktisadi ve İdari Bilimler Fakültesi Dergisi, 10(19), 214-235.

Cakmak, I. (2016). The Role of Brand Awareness on Brand Image, Perceived Quality and Effect on Risk in Create Brand Trust. New Trends and Issues Proceedings on Humanities and Social Sciences, 2(2), 177-186.

Durianto, D. (2004). Brand Equity: Strategi Memimpin Pasar. Jakarta: PT. Gramedia Pustaka Utama.

Iskandar, H., \&Berlianto, M. P. (2018). Analisis Pengaruh Brand Image, Perceived Price, Trust danValue TerhadapBehavioral IntentionPengguna Smartphone Samsung Galaxy S8. Prosiding Seminar Nasional: Manajemen, Akuntansi, dan Perbankan, 1(1), 33-49.

Keller, K. L. (2013). Strategic Brand Management: Building, Measuring, and Managing Brand Equity (Fourth Edition). Boston: Pearson.

Kinnear, T. C., \& Taylor, J. R. (1995). Riset Pemasaran: Pendekatan Terpadu Edisi 3 Jilid 1. Jakarta: Erlangga.

Kotler, P. (2005). Manajemen Pemasaran. Jilid I dan II. Jakarta: PT. Indeks Kelompok Gramedia.

,\& Armstrong, G. (2008). Prinsip-prinsip Pemasaran Jilid 1. Jakarta: Erlangga.

,\& Keller, K.L. (2009). Manajemen Pemasaran Edisi 13 Jilid 1. Jakarta: Erlangga.

Laksana, F. (2008). Manajemen Pemasaran. Yogyakarta: Graha Ilmu.

Lee, S. A., Oh, H., \& Hsu, C. H. (2017). Country-of-Operation and Brand Images: Evidence From The Chinese Hotel Industry. International Journal of Contemporary Hospitality Management, 29(7), 1814-1833.

Lien, C. H., Wen, M. J., Huang, L. C., \& Wu, K. L. (2015). Online Hotel Booking: The Effects of Brand Image, Price, Trust and Value on Purchase Intentions. Asia Pacific Management Review, 20(4), 210-218.

Lomboan, L. K. (2017). Analysis The Influence ofPerceived Quality, Perceived Price and Perceived Value onConsumer Purchase Intention inTraditional Fabrics (Case Study Kaeng Manado). Jurnal Berkala Ilmiah Efisiensi, 17(01),100-112.

Moslehpour. M.,Aulia, C. K., \& Masarie, C. E. (2015). Bakery Product Perception and Purchase Intention of Indonesian Consumers in Taiwan. International Journal of Business and Information, 10(1), 63-94.

Mowen, J.C., \& Minor, M. (2007). Perilaku Konsumen Jilid 1 Edisi Kedelapan.Jakarta: PT. Penerbit Erlangga.

Peter, J.P., \& Olson, J.C. (2013). Perilaku Konsumen dan Strategi Pemasaran Edisi Kesembilan. Jakarta: Salemba Empat.

Tansil, M. J., \& Tielung, M. V. (2014). The Effect of Perceived Price and Perceived Quality on Purchase Intention at Shmily Cupcakes Store Manado. Jurnal EMBA: Jurnal Riset Ekonomi, Manajemen, Bisnis dan Akuntansi, 2(3), 1290-1299.

Saleem, A., Ghafar, A., Ibrahim, M., Yousuf, M., \& Ahmed, N. (2015). Product Perceived Quality and Purchase Intention with Consumer Satisfaction. Global journal of management and business research, 15(1), 20-28.

Schiffman, L. G., \&Kanuk, L. L. (2007). Perilaku Konsumen Edisi Ketujuh. Jakarta: PT. Indeks.

Setiadi, N. J., (2003).Perilaku Konsumen : Konsep dan Implikasi untuk Strategi dan Penelitian Pemasaran. Jakarta : Prenada Media. 
Suarjana, I. K., \& Suprapti, N. W. S. (2018). Pengaruh Persepsi Harga, Pengetahuan Produk, Dan Citra Perusahaan Terhadap Niat Beli Layanan Multi Servis Merek Indihome. EJurnal Manajemen Universitas Udayana, 7(4), 1920-1949.

Suhud, U., \& Willson, G. (2019). Low-Cost Green Car Purchase Intention: Measuring The Role Of Brand Image On Perceived Price and Quality.European Research Studies Journal, 22(3), 282-293.

Tee, P. K., Gharleghi, B., Chan, B., Samadi, B., \&Balahmar, A. A. (2015). Purchase Intention of International Branded Clothes Fashion among Younger's in Jakarta. International Journal of Business and Social Research, 5(8), 08-17.

Wang, Y. H., \& Chen, L. Y. (2016). An empirical study of the effect of perceived price on purchase intention evidence from low-cost carriers. International Journal of Business and Social Science, 7(4), 97-107.

, \& Tsai, C. F. (2014). The relationship between brand image and purchase intention: Evidence from award winning mutual funds. The international journal of business and finance research, 8(2), 27-40. 